\title{
COMPARATIVE STUDY OF CYSTIC SWELLINGS OF SCROTUM IN ADULT PATIENTS
}

\author{
P. Karuppasamy1, Sanjeeva Raju Kunche2, M. Shanmugapathy3
}

${ }_{1}^{1}$ Assistant Professor, Department of General Surgery, SVMCH, Ariyur, Pondicherry, India. ${ }^{2}$ Assistant Professor, Department of General Surgery, SVMCH, Ariyur, Pondicherry, India. ${ }^{3}$ Assistant Professor, Department of General Surgery, SVMCH, Ariyur, Pondicherry, India.

ABSTRACT
BACKGROUND
Cystic swellings of the scrotum are common clinical entities that surgeons encounter in daily practice. Males of all ages are affected.
Today, considerable heterogeneity exists in their treatment. This study sought to identify the prevalence and patterns of
presentation of these swellings in adults and evaluate the different modalities of surgical management.

\section{MATERIALS AND METHODS}

A cross-sectional study was undertaken from January 2016 to December 2018. A total of 372 patients fulfilling the inclusion criteria were included. Data was collected using a proforma. All patients were surgically managed.

\section{RESULTS}

Majority of cases (28\%) were observed between 41-50 years (mean age 43.9 years). In $71 \%$, mode of presentation was a painless, gradually progressive swelling. Mean duration of symptoms was 17.3 months. Primary vaginal hydrocele was the commonest swelling encountered (in 73.1\%). Jaboulay's procedure was undertaken in 75.2\% of patients. Lord's plication was associated with a comparatively shorter operative time, lesser postoperative scrotal oedema and a shorter hospital stay. Epididymal cysts accounted for $19.4 \%$ and were managed by excision. The most common complication observed irrespective of surgery performed was scrotal oedema (in 36\%). Haematoma and infection were less frequently observed. Patients were followed-up for a mean period of 1.8 months. No recurrences were detected during this period.

\section{CONCLUSION}

Cystic swellings of the scrotum are conditions predominantly affecting middle-aged males. Among these, primary hydrocele is the commonest. Although Lord's plication is simpler and gives good results with fewer complications, Jaboulay's procedure remains the gold standard for surgical management of hydrocele.

\section{KEY WORDS}

Epididymal Cyst, Hydrocele, Jaboulay's Procedure, Lord's Placation

HOW TO CITE THIS ARTICLE: Karuppasamy P, Kunche SR, Shanmugapathy M. Comparative study of cystic swellings of scrotum in adult patients. J. Evolution Med. Dent. Sci. 2019;8(11):777-782, DOI: 10.14260/jemds/2019/171

\section{BACKGROUND}

Scrotum is a cutaneous bag containing the right and left testes, the epididymis and the lower parts of the spermatic cord. ${ }^{1}$ Cystic swelling is defined as abnormal collections of fluid within the scrotal cavity; they affect males of all age groups and account for the majority of all scrotal swellings.

Although easily detectable, the vast majority remains asymptomatic, and attain a considerable size before causing discomfort to the patient. ${ }^{2}$ Most patients, however, hesitate to seek medical attention during the early stages, these swellings being a source of embarrassment and due to a lack of awareness. This results in considerable physical, psychological, social, and economic distress. ${ }^{3}$ These patients often present late with complications. Hence, although mortality associated with this condition is negligible, morbidity can be significant. The etiology of the cystic causes of scrotal enlargement is diverse, it ranges from hydrocoele

'Financial or Other Competing Interest': None.

Submission 11-01-2019, Peer Review 02-03-2019,

Acceptance 08-03-2019, Published 18-03-2019.

Corresponding Author:

Dr. P. Karuppasamy,

SVMC \& RC,

Ariyur, Pondicherry,

India.

E-mail: karuppasamy01@yahoo.co.in

DOI: $10.14260 /$ jemds $/ 2019 / 171$

\section{(c) $(\mathrm{i}) \Theta$}

(The most common cause of such swellings), to spermatocoele and epididymal cyst to less common ones like haematocoele, pyocoele and chylocoele. Most of these swellings are benign. ${ }^{4}$ Even so, an accurate diagnosis is crucial; acute conditions such as pyoceles and haematoceles require prompt intervention to prevent irreversible testicular injury. Conditions like old clotted hematoceles may simulate malignancy clinically and testicular malignancy itself may present as a secondary hydrocele. The gold standard treatment for cystic swellings of the scrotum is surgery irrespective of the etiopathogenesis. A number of operative interventions have been advocated each of them with unique post-operative complications and different rates of recurrence. ${ }^{5}$ For the treatment of idiopathic hydrocele, the majority are variations of three primary procedures: excision, eversion and window or internal drainage procedures. ${ }^{6}$ The commonly performed operative interventions such as Jabouley's partial excision and eversion, Lord's plication, radical excision and vaginal fenestration may be considered modifications of the above basic techniques. ${ }^{7}$ A study was done to evaluate the role of ultrasound investigation in scrotal swelling. They observed that the cause of scrotal swelling was mainly extra-testicular, hydrocele being commonest of intra-testicular causes, infection and tumor were commonest. They concluded ultrasound examination distinguishes extra-testicular from intra-testicular cases of 
scrotal swellings. ${ }^{8}$ Epididymal cysts and spermatocoeles are treated by excision. Pyoceles and hematoceles, when presenting early, may be managed by incision and drainage. Intraoperative complications most commonly encountered following surgery include hemorrhage, injury to cord structures and torsion testis due to faulty positioning. Postoperative complications include edema, hematoma formation, infection and recurrence. ${ }^{9}$ This study sought to identify the age wise distribution, clinical patterns of presentation, the varied etiology and related predisposing factors for different types of cystic swellings of the scrotum in adults. The various modalities of surgical treatment presently available were also compared with regard to post-operative complications and recurrence rates.

\section{Objectives}

To study the age-related frequency of cystic swellings of scrotum, mean duration of symptoms of patients with cystic swelling of scrotum, side distribution, surgical management, mean duration of hospital stay for various procedures.

\section{MATERIALS AND METHODS}

It is a descriptive study. Patients admitted for the treatment of cystic swellings of the scrotum were consecutively selected from January 2015 to December 2018. A total of 372 cases were identified and included in the study. The study design was cross sectional.

\section{Inclusion Criteria}

- In-patients with a diagnosis of cystic swellings of the scrotum admitted to Sri Venkateswaraa Medical College Hospital \& Research centre, Ariyur, Puducherry during January 2015 to December 2018.

- Patients willing to give written informed consent.

- Patients aged 18 years and above.

- All intrascrotal and extra testicular swellings.

\section{Exclusion Criteria}

- Patients with severe infection and those who are seriously ill.

- Swellings arising from the skin of the scrotum.

After obtaining ethical committee approval, in-patients with cystic swellings of the scrotum fulfilling the inclusion criteria and consenting to participate were enrolled in the study. The data obtained was recorded in a predesigned proforma. Diagnosis was clinical and supported by scrotal ultrasonography in all cases. All cases were treated surgically. The specific surgical intervention to be undertaken and the anaesthesia required were decided by the attending surgeon based on the clinical and radiological findings.

Preoperatively, antimicrobial prophylaxis using intravenous cefotaxime was given in all patients. Relevant intraoperative findings were noted. The time taken for completion of the various procedures was recorded. Rubber corrugated drains were used when indicated as per the discretion of the surgeon and removed within 48 hours. All patients were given scrotal support and appropriate antibiotics, analgesics and anti-inflammatory medication.

Postoperative course and the incidence and management of surgical complications, if any, were recorded. All complications were managed conservatively. Patients were counseled regarding follow-up at the time of discharge.

\section{RESULTS}

In the present study of 372 patients, the mean age of presentation was 43.9 years. The youngest patient in the study population presented at the age of 18 years and the oldest at the age of 76 years. The maximum number of subjects was seen in the 41-50 years age group $(n=52)$ accounting for $28 \%$, followed by the $31-40$ years age group $(n=43)$. This distribution remained unchanged even when comparing the age at presentation of the different types of cystic swellings with most cases clustered in the 41-50 years age bracket (Table 1).

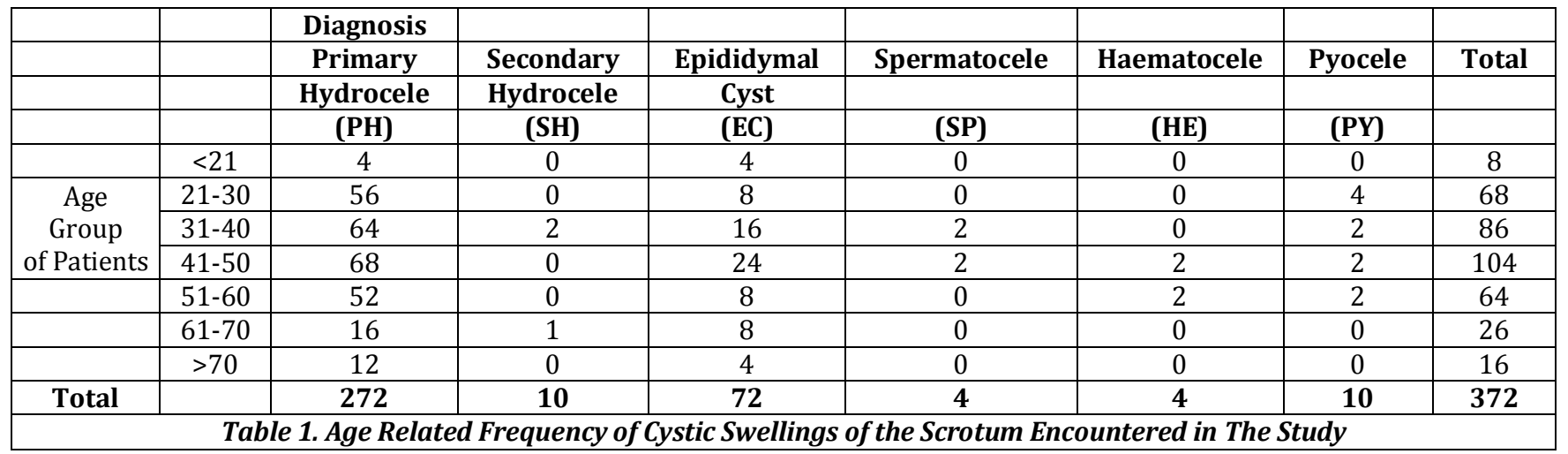

\begin{tabular}{|c|c|c|c|c|c|c|}
\hline Diagnosis & Mean & N & Std. Deviation & Minimum & Maximum & Range \\
\hline Primary Hydrocele (PH) & 18.9853 & 272 & 6.21704 & 8.00 & 36.00 & 28.00 \\
\hline Secondary Hydrocele (SH) & 6.6000 & 10 & 3.13050 & 4.00 & 12.00 & 8.00 \\
\hline Epididymal Cyst (EC) & 14.7222 & 72 & 4.63287 & 8.00 & 24.00 & 16.00 \\
\hline Spermatocele (SP) & 21.0000 & 4 & 4.24264 & 18.00 & 24.00 & 6.00 \\
\hline Haematocele (HE) & 6.0000 & 4 & .00000 & 6.00 & 6.00 & .00 \\
\hline Pyocele (PY) & 3.6000 & 10 & 1.81659 & 1.00 & 6.00 & 5.00 \\
\hline Total & $\mathbf{1 7 . 2 9 5 7}$ & $\mathbf{3 7 2}$ & $\mathbf{6 . 7 6 1 8 7}$ & $\mathbf{1 . 0 0}$ & $\mathbf{3 6 . 0 0}$ & $\mathbf{3 5 . 0 0}$ \\
\hline
\end{tabular}


Hydrocele was the most common cystic swelling of the scrotum encountered. It comprised $75.8 \%$ of the study population. Epididymal cysts accounted for $19.4 \%$ of the study population.

Mean duration of symptoms for patients with cystic swellings of the scrotum was 17.3 months. It ranged from one month to three years (Table 2).

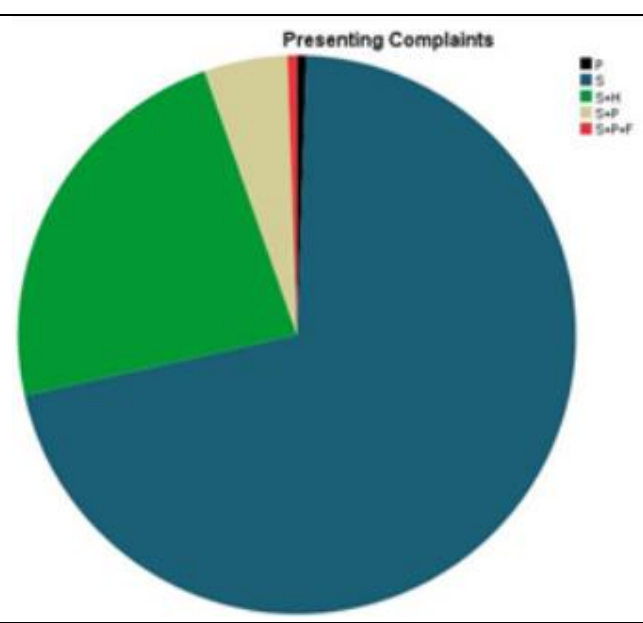

Figure 1. Presenting Complaints of Subjects included in The Study (P: Pain, S: Swelling, H: Heaviness, F: Fever)

Of the 372 subjects, $71 \%$ had no symptoms apart from the swelling. In $23.1 \%$ of subjects, swelling was associated with heaviness (Figure 1). Right sided swellings were found to be more common (Table 3).

\begin{tabular}{|c|c|c|c|c|c|c|c|c|}
\hline & & \multicolumn{2}{|c|}{ Diagnosis } & & & & \\
\hline & & PH & SH & EC & SP & HE & PY & Total \\
\hline \multirow{2}{*}{$\begin{array}{c}\text { Side of The } \\
\text { Swelling }\end{array}$} & Right & 120 & 6 & 24 & 4 & 2 & 6 & 162 \\
\cline { 2 - 9 } & Left & 104 & 2 & 28 & 0 & 2 & 4 & 140 \\
\cline { 2 - 9 } & Bilateral & 48 & 2 & 20 & 0 & 0 & 0 & 70 \\
\hline Total & $\mathbf{2 7 2}$ & $\mathbf{1 0}$ & $\mathbf{7 2}$ & $\mathbf{4}$ & $\mathbf{4}$ & $\mathbf{1 0}$ & $\mathbf{3 7 2}$ \\
\hline \multicolumn{7}{|c}{} \\
\end{tabular}

\begin{tabular}{|c|c|c|c|c|c|c|c|}
\hline & & \multicolumn{2}{|c|}{ Type of Surgery Performed } & \multirow[b]{2}{*}{ Excision } & \multirow[b]{2}{*}{$\begin{array}{c}\text { Incision } \\
\text { Drainage }\end{array}$} & \multirow[b]{2}{*}{ Orchidectomy } & \multirow[b]{2}{*}{ Total } \\
\hline & & Jabouleys & Lords Plication & & & & \\
\hline & & (JB) & (LP) & $(\mathrm{EX})$ & (ID) & (OR) & \\
\hline & $\mathrm{PH}$ & 204 & 64 & 0 & 0 & 4 & 272 \\
\hline & $\mathrm{SH}$ & 8 & 0 & 0 & 0 & 2 & 10 \\
\hline & EC & 0 & 0 & 72 & 0 & 0 & 72 \\
\hline & SP & 0 & 0 & 4 & 0 & 0 & 4 \\
\hline & $\mathrm{HE}$ & 0 & 0 & 0 & 0 & 4 & 4 \\
\hline & PY & 0 & 0 & 0 & 2 & 8 & 10 \\
\hline Total & & 212 & 64 & 76 & 2 & 18 & 372 \\
\hline
\end{tabular}

\begin{tabular}{|c|c|c|c|c|c|c|}
\hline Type of Surgery Performed & Mean & $\mathbf{N}$ & Std. Deviation & Minimum & Maximum & Range \\
\hline Jabouleys (JB) & 4.5849 & 212 & 1.11157 & 3.00 & 8.00 & 5.00 \\
\hline Lords Plication (LP) & 3.1250 & 64 & 1.18458 & 2.00 & 7.00 & 5.00 \\
\hline Excision (EX) & 3.8684 & 76 & 1.09473 & 3.00 & 8.00 & 5.00 \\
\hline Incision Drainage (ID) & 7.0000 & 2 &. & 7.00 & 7.00 & .00 \\
\hline Orchidectomy (OR) & 6.7778 & 18 & .97183 & 5.00 & 8.00 & 3.00 \\
\hline Total \\
Table 5. The Mean Duration of Hospital Stay for Various Surgical Modalities of Treatment
\end{tabular}

The most commonly performed surgery was Jabouley's procedure (In $57 \%$ of patients). Lord's plication was performed in $17.2 \%$ and excision in $20.4 \%$ (Table 4 ).

Post-operative complications (As evidenced by scrotal wall edema, hematoma formation or infection) was seen in $50 \%$ of patients undergoing Jabouley's procedure and $12.5 \%$ of those undergoing Lord's plication.
Six of the 76 patients who underwent excision and 12 of the 18 patients who underwent orchidectomy developed this complication (Figure 3).

The mean duration of hospital stay for the various surgical modalities of treatment was 4.3 days (Table 5).

The average duration of follow-up was 1.8 months (ranging from 0 to 4 months). 


\section{DISCUSSION}

Scrotal masses may occur at any age from infancy to senescence, with the underlying causes distributed evenly across the age spectrum. ${ }^{10,11}$

As evident in this study, $51.1 \%$ of males included were in the economically productive age group of $31-50$ years. As chronic conditions affecting males, the peak incidence of cystic swellings of the scrotum at this age can pose a significant economic burden for the patient and his dependants and have psychosocial implications. Other studies too have reported similar results. In the study conducted by Ku et al (2001), most of the patients belonged to the age group of 41-50 years with a range of 16 to 83 years. ${ }^{6}$ Subith et al (2014), in their assessment of 170 cases of cystic scrotal swellings, observed that $40 \%$ of patients were between 31 and 40 years of age. 12

Clinical examination was adequate to establish the diagnosis. Nevertheless, all patients were subjected to a scrotal ultrasound in order to confirm the diagnosis and rule out concomitant testicular pathology. Hydrocele was the most common cystic swelling of the scrotum encountered in all age groups. No precipitating cause could be detected in 272 cases; these cases were labeled as primary or idiopathic. of the cases of secondary hydrocele, 8 developed following previous episodes of epididymo-orchitis. One patient with a hydrocele was found to have an underlying testicular malignancy on scrotal ultrasound.

The mean age at presentation of these swellings was 43.3 years. These findings are in agreement with those of Leung et al. In their study involving scrotal sonological imaging in asymptomatic subjects, they concluded that hydroceles affect approximately $1 \%$ of adults and the primary variety was seen most commonly in men older than the age of 40.11

The other swellings commonly encountered were epididymal cysts (Accounting for $19.4 \%$ of cases). The difference in average age at presentation for the various cystic swellings was not found to be statistically significant.

Primary vaginal hydroceles are more commonly right sided. In the present study, $44.1 \%$ of idiopathic hydroceles were right sided and $17.7 \%$ were found to be bilateral. Although hydroceles are considered to be bilateral in $7-10 \%$ of patients, this figure has been known to vary markedly in different studies. ${ }^{2}$ This apart, 20 cases of epididymal cyst and 4 case of secondary hydrocele were found to be bilateral.

With regard to the mode of presentation, $71 \%$ of patients had no symptoms apart from the swelling. In $23.1 \%$ of subjects, swelling was associated with a dragging sensation more appreciable after exertion or towards the end of the day. It was more commonly seen with large swellings of longstanding duration. Swelling with pain and fever were seen in patients with acute infective conditions of the scrotum. The mode of presentation has been reflected in other studies conducted on cystic swellings of the scrotum as well. Subith et al (2014) found that scrotal swelling was the presenting complaint in $59 \%$ of cases. It was associated with pain in $28 \%$. In the majority comprising $46 \%$ of patients, the mean duration of swelling before presentation was 1-2 years. In $17 \%$, the duration of symptoms was for more than 2 years. ${ }^{13}$

In this study, the average duration of symptoms before presentation was 17.3 months. Secondary hydrocele, haematocele and pyocele had a more acute presentation since these were often associated with pain and constitutional symptoms which prompted patients to seek medical advice early.

Surgical management under spinal anaesthesia was employed in all patients in the study population. Intraoperatively, the appearance of the testis, epididymis and spermatic cord were noted. Although orchidectomy is not the standard of treatment in cases of haematocele and pyocele, long standing cases are often associated with atrophy and devitalization of the testes. The testes in these instances are not viable. Also, a number of cases treated with broad spectrum antibiotics and surgical drainage ultimately require orchidectomy. ${ }^{14,15}$ In the present study, scrotal ultrasound was used to assess preoperative status of the testes in all patients. The testes were found to be atrophic and avascular in 16 patients. These subjects were counselled regarding the nature of disease and the need for orchidectomy. Prior informed written consent was taken from the patient and his relatives before this procedure. One patient with a hydrocele secondary to testicular malignancy underwent a high inguinal orchidectomy.

Primary vaginal hydrocele was managed by either Lord's plication or Jabouley's procedure based on the merits of the case and the discretion of the attending surgeon. Jabouley's excision and eversion of the sac was the most commonly performed surgical procedure in this study; it was undertaken in 212 patients with large, floppy hydrocele sacs, of which 4 were secondary hydroceles. Lord's plication was performed in 64 patients with small, thin walled sacs.

Complications following scrotal surgery have been extensively evaluated in literature. According to a descriptive study conducted by Kiddoo et al (2004), the overall complication rate following outpatient scrotal surgery was $19.2 \%$ and the most common complications witnessed after surgery for hydroceles and spermatoceles were persistent scrotal swelling, inflammation and postoperative infection. ${ }^{9}$ Other less frequent ones include recurrence, injury to spermatic vessels, and chronic pain.

In another descriptive study comparing the frequency of complications after surgery for benign scrotal conditions, Swartz et al reported that the overall complication rate was $20 \%$ and included recurrence or persistent swelling $(6 \%)$, hematoma (5\%), and infections (3.6\%); $95 \%$ of complications were seen after hydrocelectomy. 16

Scrotal oedema is considered the most common complication following hydrocele surgery. Studies have shown that techniques involving extensive dissection to mobilize the hydrocele sac are most likely to result in this complication. Incidence of scrotal swelling was also found to correlate with the volume of the hydrocele. ${ }^{17}$

In our study too, the most common complication observed irrespective of the operation performed was persistent oedema. Overall, it was seen in $36 \%$ of patients.

On comparing the procedures for hydrocele, edema was observed more frequently in patients undergoing Jabouley's procedure (50\%), possibly due to the extent of dissection undertaken to mobilize the sac. Edema was seen in only 8 of the 64 patients $(12.5 \%)$ who underwent Lord's plication.

These findings are similar to observations made by other authors. Rodriguez et al compared the complication rates of various techniques and found that hydrocele excision was followed by marked edema in $76 \%$ of cases and Jabouley's technique to have rate of $91 \%$. Both procedures involved 
extensive mobilisation of the sac. In contrast, Lord's plication technique which does not require dissection of the hydrocele sac from the dartos layer had a $10 \%$ rate of postoperative oedema. ${ }^{16} \mathrm{Ku}$ et al also found a similar variation in the rates of scrotal edema after sac excision and Lord's procedure ( $74 \%$ and $8 \%$ respectively). ${ }^{18}$

Hematoma formation and surgical site infection are other common complication after scrotal surgery. The various procedures have different rates of hematoma formation, the degree of dissection involved while mobilizing the hydrocele sac is pivotal in pathogenesis. In the present study, 14 of the 212 patients $(6.6 \%)$ who underwent Jabouley's procedure developed hematoma formation.

This complication was not seen in patients undergoing Lord's plication. Five of the 212 patients (4.7\%) in the Jabouley's procedure group developed surgical site infection whereas 4 patients who had undergone Lord's plication developed this complication (6.3\%). In this study, all complications observed were managed conservatively. Broad spectrum antibiotics, scrotal support and analgesics were used, and any hematoma or pus collection was evacuated.

Although, Lord's plication appears to be more advantageous than Jabouley's procedure in terms of postoperative complications and duration of hospital stay, it may not be appropriate in all cases of hydrocele. Plication of thick walled secondary and long-standing hydrocele sacs can result in a residual mass of plicated tissue in the scrotum. These cases are best managed with partial excision and eversion of the sac. Hence, Jabouley's procedure is considered the surgical modality of choice for management of hydroceles. Epididymal cysts were the second most common cystic swellings noted in this study. These cystic lesions of the scrotal cavity were treated by excision. Two cases of spermatocele were diagnosed following histopathological examination of the specimen. As for the complications, three patients developed scrotal edema and of these, one was associated with a hematoma formation. One case of pyocele was incised and drained with supportive antibiotics and analgesics.

Recurrence rates have been historically similar among the various procedures. Of the three basic techniques for hydrocele, excision and eversion procedures have a 0 to $4 \%$ risk of recurrence. 18,19 Patients were discharged after an average of 4.3 days in the hospital. The average duration of follow-up was 1.8 months (ranging from 0 to 4 months). No recurrences were noted during this period.

\section{CONCLUSION}

Cystic swellings of the scrotum are common conditions that a surgeon comes across in daily practice. They are often associated with considerable morbidity in terms of physical, psychological, social, and economic outcomes.

Males of all age groups may be affected, the most common mode of presentation being a painless, gradually progressive swelling in the scrotum. Hydrocele was the most common swelling encountered in all age groups. The other swellings encountered were epididymal cysts and pyoceles. All patients were managed surgically. Primary vaginal hydrocele was managed by either Jabouley's procedure or Lord's plication based on the merits of the case. Lord's plication was associated with lesser postoperative complications and a shorter hospital stay. However, it may not be appropriate in cases of thick walled, secondary and long-standing hydroceles. Such cases are best managed with partial excision and eversion of the sac. Hence, Jabouley's procedure is considered the surgical modality of choice for management of hydroceles.

Epididymal cysts and spermatoceles were treated by excision. An orchidectomy was undertaken in cases where the testis was found to be atrophic, devitalized or when it was suspected to be harboring malignancy. The most common complication observed in the study population was persistent scrotal oedema. Other commonly observed ones were hematoma and surgical site infection. All complications were managed conservatively. Follow up for up to 4 months was undertaken. No recurrences were detected during this period.

\section{REFERENCES}

[1] Chaurasia BD. Human anatomy. $4^{\text {th }}$ edn. CBS Publishers and Distributors 2004;2:215.

[2] Valentino M, Barozzi L, Pavlica P, et al. Imaging scrotal lumps in adults 2: cysts and fluid collections. In: Bertolotto M, Trombetta C, eds. Scrotal pathology, medical radiology, diagnostic imaging. Berlin, Heidelberg: Springer-Verlag 2012: p. 180-7.

[3] Lasheen A. Hydrocelectomy through the inguinal approach versus scrotal approach for idiopathic hydrocele in adults. J Arab Society Medical Research 2012;7(2):68-72.

[4] Nesbit JA. Hydrocele and spermatocele. In: Graham SD Jr, Keane TE, Glenn JF, eds. Glenn's Urologic Surgery. $7^{\text {th }}$ edn. Philadelphia: Lippincott Williams and Wilkins 2004: p. 528-32.

[5] Kavoussi PK, Costabile RA. Surgery of the scrotum and seminal vesicles. In: Wein AJ, Kavoussi LR, Novick AC, et al. Campbell Walsh Urology. 10 th edn. Philadelphia: Saunders Elsevier 2012: p. 1008-11.

[6] Rochelle JC, Levine LA. Complications of benign adult penile and scrotal surgery. In: Loughlin KR, edr. Complications of urologic surgery and practice: diagnosis, prevention and management. Boca Raton, FL: CRC Press 2007: p. 229-30.

[7] Ku JH, Kim ME, Lee NK, et al. The excisional, plication and internal drainage techniques: a comparison of the results for idiopathic hydrocele. BJU Int 2001;87(1):82-4.

[8] Micallef M, Torreggiani WC, Hurley M, et al. The ultrasound investigation of scrotal swelling. Int J STD AIDS 2000;11(5):297-302.

[9] Kiddoo DA, Wollin TA, Mador DR. A population based assessment of complications following Outpatient hydrocelectomy and spermatocelectomy. J Urol 2004;171(2 Pt 1):746-8.

[10] Woodward PJ, Schwab CM, Sesterhenn IA. From the archives of the AFIP: extratesticular scrotal masses: radiologic - pathologic correlation. Radiographics 2003;23(1):215-40.

[11] Rubenstein RA, Dogra VS, Seftel AD, et al. Benign intrascrotal lesions. J Urol 2004;171(5):1765-72.

[12] Kumar SK, Sasikumar J, Seetharamaiah T, et al. Cystic swellings of scrotum: management. Int J Med Res Health Sci 2014;3(2):338-41. 
[13] Leung ML, Gooding GA, Williams RD. High resolution sonography of scrotal contents in asymptomatic subjects. Am J Roentgenol 1984;143(1):161-4.

[14] Slavis SA, Kollin J, Miller JB. Pyocele of the scrotum: consequence of spontaneous rupture of testicular abscess. Urology 1989;33(4):313-6.

[15] Bruner DI, Ventura EL, Devlin JJ. Scrotal pyocele: uncommon urologic emergency. J Emergencies Trauma Shock 2012;5(2):206.

[16] Swartz MA, Morgan TM, Krieger JN. Complications of scrotal surgery for benign conditions. Urology 2007;69(4):616-9.
[17] Kim JK, Shin JH, Lim JS. A 10-year retrospective study of the operative treatment results of adult type hydrocele. Korean J Urol 2008;49(1):82-7.

[18] Rodríguez WC, Rodríguez DD, Fortuño RF. The operative treatment of hydrocele: a comparison of four basic techniques. J Urol 1981;12(6):804-5.

[19] Jahnson S, Johansson JE. Results of window operation for primary hydrocele. Urology 1993;41(1):27-8. 